\title{
Effects of adrenergic and cholinergic drugs on electrical and mechanical activities of the rat cauda epididymidis in vitro
}

\author{
Leena Laitinen and A. Talo \\ Department of Biology, Laboratory of Animal Physiology, University of Turku, \\ 20500 Turku 50, Finland
}

\begin{abstract}
Summary. Electrical and mechanical activities of the rat epididymis (at $29 \pm 1.1 \mathrm{~cm}$ from the junction of the vas deferens) were recorded in vitro. The frequency of the spontaneous activity was $2.7 \pm 0.15 / \mathrm{min}$. Adrenaline, phenylephrine, isoprenaline and carbachol increased the basal tension, frequency and amplitude of the contractions. Phentolamine, an alpha-adrenergic blocking agent, abolished the stimulatory effects of adrenaline and isoprenaline, but not those of carbachol. Propranolol and metoprolol, beta-adrenergic blocking agents, did not inhibit the stimulatory effects of isoprenaline. Atropine abolished the response to carbachol. The results suggest that alpha-adrenergic receptors but not beta-receptors are present in the rat epididymis.
\end{abstract}

\section{Introduction}

It is generally accepted that the smooth muscle of the epididymal duct contracts spontaneously and rhythmically, with the frequency decreasing from the caput towards the cauda epididymidis and from the cauda to the vas deferens (Risley, 1963; Talo, Jaakkola \& Markkula-Viitanen, 1979). The vas deferens is normally quiescent. The innervation of the vas deferens and the cauda epididymidis is dense (Baumgarten, Holstein \& Rosengren, 1971), and sudden, powerful contractions of these ducts occur during ejaculation.

The influence of various drugs on the spontaneous contractions of the male accessory genital organs has been investigated in vitro (Hib \& Caldeyro-Barcia, 1974; Hib, 1975; da Silva e Souza, Gimeno \& Gimeno, 1975) and in vivo (Melin, 1970; Knight, 1974; Hib, 1976) but the area for the recordings has either been limited or not specified.

The present work utilized two methods for studying the effects of various drugs on spontaneous contractility at defined locations of the distal part of the cauda epididymidis.

\section{Materials and Methods}

Male albino Sprague-Dawley rats, weighing $250-350 \mathrm{~g}$ and caged separately from females, were lightly anaesthetized with ether and killed by decapitation. The testis, the epididymis and vas deferens were removed and immediately placed in fresh, oxygenated $\left(95 \% \mathrm{O}_{2}, 5 \% \mathrm{CO}_{2}\right)$ modified Ringer solution (154 mM-NaCl, $5.6 \mathrm{~mm}-\mathrm{KCl}, 0.12 \mathrm{mM}-\mathrm{MgCl}_{2}, 2.2 \mathrm{mM}-\mathrm{CaCl}_{2}, 5.9$ $\mathrm{mM}-\mathrm{NaHCO}_{3}, 2.5 \mathrm{~mm}$-glucose; $\left.\mathrm{pH} 7.4\right)$ at room temperature $\left(22^{\circ} \mathrm{C}\right)$. A small section of the 
cauda epididymidis at a mean \pm s.e.m. distance of $29 \pm 1 \cdot 1 \mathrm{~cm}(n=64)$ from the junction of the epididymis and vas deferens was freed from the surrounding connective tissue. For the recordings of mechanical activity, pieces of the epididymal duct $10 \pm 1 \mathrm{~mm}$ in length were immersed in a tissue bath containing $10 \mathrm{ml}$ modified Ringer solution, gassed with a mixture of

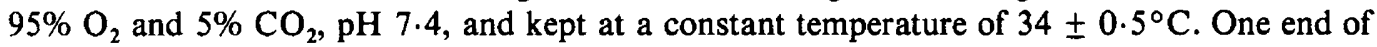
the tissue was attached to a Grass FT 0.3 isometric tension transducer, and the other end to a hook at the base of the organ bath. The resting tension was adjusted to between 75 and $100 \mathrm{mg}$ because the spontaneous contractions of the epididymal duct stretched within this range were regular and of maximal amplitude. After an equilibration period of 30-45 min the drugs were added to the organ bath at 5 -min intervals in a cumulative manner to elucidate the dose-response curves. The drug concentration was increased from $10^{-9}$ to $3 \times 10^{-4} \mathrm{M}$.

For the measurements of electrical activity the testis and the epididymis were placed in an organ bath containing $25 \mathrm{ml}$ modified Ringer solution with $\mathrm{pH}$, temperature and gassing as mentioned above. The electrical activity from a portion of the epididymal duct straightened by dissection was recorded by three suction electrodes (Talo \& Hodgson, 1978) with an outer diameter of $250 \mu \mathrm{m}$. The electrodes were connected to a Grass 4-channel polygraph recorder. After an equilibration time of $30-45 \mathrm{~min}$ the drugs were added in a cumulative manner at 5-min intervals, increasing the dose in the bath from $10^{-9}$ to $3 \times 10^{-4} \mathrm{M}$. The frequency of the contractions was recorded for $5 \mathrm{~min}$. The significance of the differences was estimated by Student's $t$ test.

The drugs were dissolved in fresh, modified Ringer solution and were as follows: adrenaline (Adrenalin, Fluka AG, Buchs, Switzerland); phenylephrine hydrochloride (Neosynephrine: Winthrop, Dijon, France); isoprenaline hydrochloride (Sigma, St Louis, Missouri, U.S.A.); phentolamine (Regitin, Ciba, Basle, Switzerland); propranolol hydrochloride (Sigma); metoprolol tartrate (Hässle, Mölndal, Sweden); carbachol and atropine sulphate (Merck, Darmstadt, Germany).

\section{Results}

\section{Spontaneous activity}

Spontaneous activity was present in both the mechanical and electrical recordings. After the equilibration period the contractions were regular and lasted for hours in most experiments. The frequency of the epididymal contractions was about the same in both methods, i.e. $2 \cdot 7 \pm$ $0 \cdot 15 / \mathrm{min}$ (s.e.m.; $n=64$ ).

\section{Effects of adrenergic agonists}

Adrenaline. Adrenaline increased the frequency of the contractions significantly $(P<0.001)$ in both the electrical and mechanical experiments, the maximum responses being 11.5 and $16 /$ min, respectively (Text-fig. 1). In mechanical recordings, adrenaline led to an increase, not only in frequency, but also in the basal tension and the amplitude of the contractions, sometimes producing a short-lasting tetanus (Text-fig. 2). In electrical recordings, the responses were obtained with lower concentrations $\left(10^{-9} \mathrm{M}\right)$ than in mechanical recordings $\left(3 \times 10^{-8} \mathrm{M}\right)$, but the maximum effect was greater in the latter. The dose eliciting the maximum effect $\left(3 \times 10^{-6} \mathrm{M}\right)$ was the same for both methods.

Phenylephrine. Phenylephrine, an alpha-adrenergic agonist, had effects similar to those of adrenaline. However, higher concentrations $\left(10^{-5}\right.$ or $\left.3 \times 10^{-5} \mathrm{M}\right)$ had to be used in both types of recording to produce the maximum responses, $11-12$ contractions $/ \mathrm{min}(P<0.001$; Text-figs 2 and 3 ). The frequency curves were almost identical for both recording methods. 


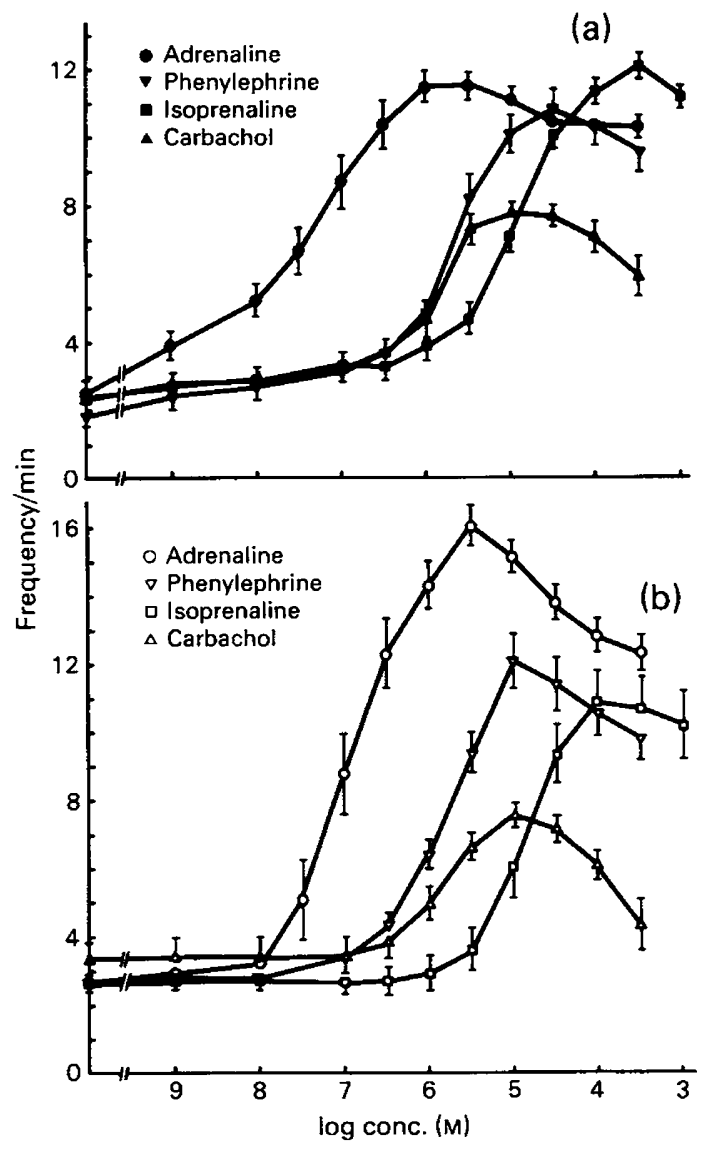

Text-fig. 1. Frequency of (a) electrical and (b) mechanical activity in the cauda epididymidis of the rat in vitro in response to various drugs. Values are mean \pm s.e.m. for 8 recordings.

Isoprenaline. Isoprenaline, a beta-adrenergic agonist, significantly increased the frequency $(P<0.001)$, basal tension and amplitude of the contractions (Text-figs $1 \mathrm{~b}$ and 2$)$, but the doses needed to elicit the maximum responses were fairly high, $10^{-4}$ to $10^{-3} \mathrm{M}$. The frequency curves from mechanical and electrical recordings were similar. The maximum frequencies produced by the drug were 11-12 contractions/min (Text-fig. 1).

\section{Effect of a cholinergic agonist}

Carbachol. Carbachol significantly increased the frequency of the epididymal contractions $(P<0.001)$ but to a lesser extent than the adrenergic agonists. The maximum effect, $7-8$ contractions/min, was produced by a dose of $10^{-5} \mathrm{M}$ (Text-fig. 1). Basal tension and amplitude were also increased but the effect on the basal tension was not very great (Text-fig. 2). The dose-response curves for frequency were similar for both types of recording.

\section{Effect of receptor blockers}

Phentolamine. The tissues were exposed to this alpha-adrenergic blocker in concentrations ranging from $10^{-8}$ to $10^{-3} \mathrm{M}$. No significant changes in the spontaneous contractions, recorded 


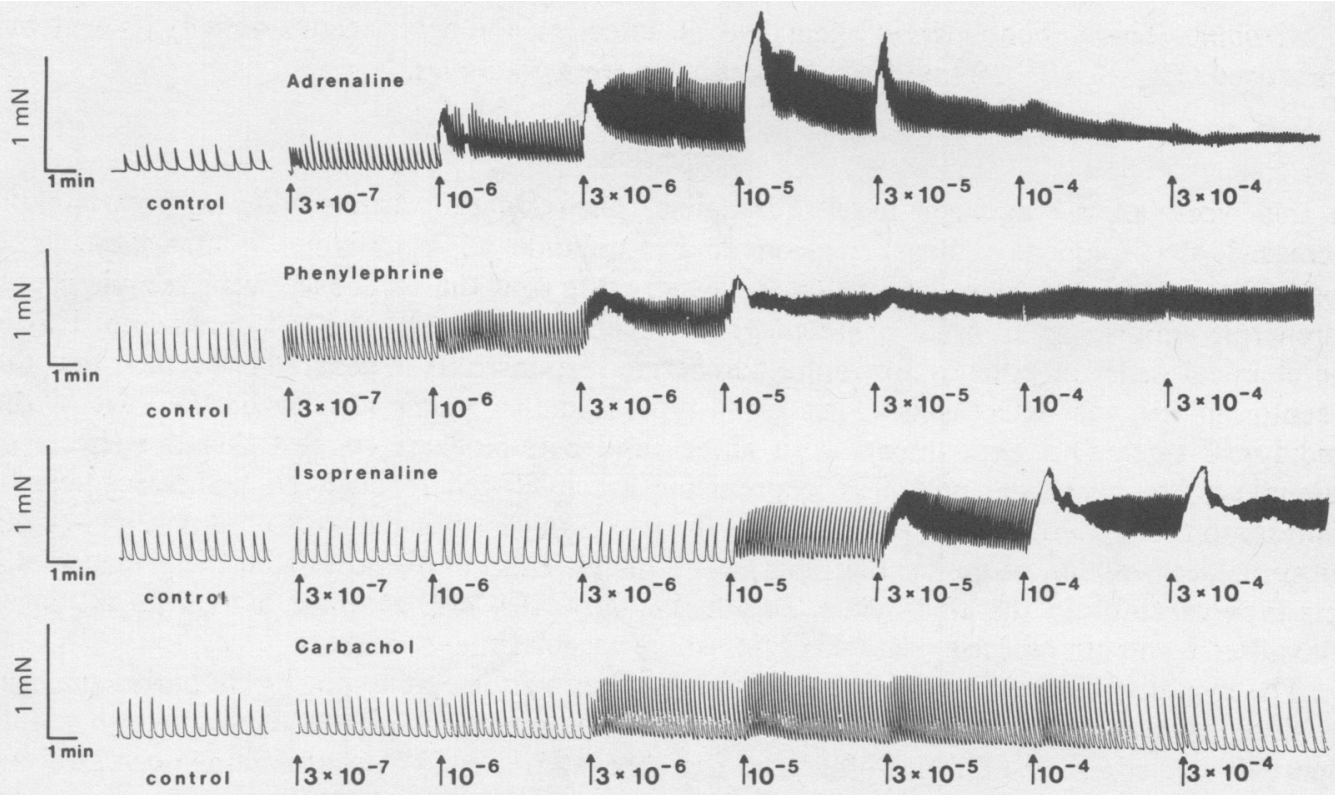

Text-fig. 2. Recordings of mechanical activity in the rat cauda epididymidis in response to increasing doses (M) of adrenaline, phenylephrine, isoprenaline and carbachol at the times indicated (arrowed).
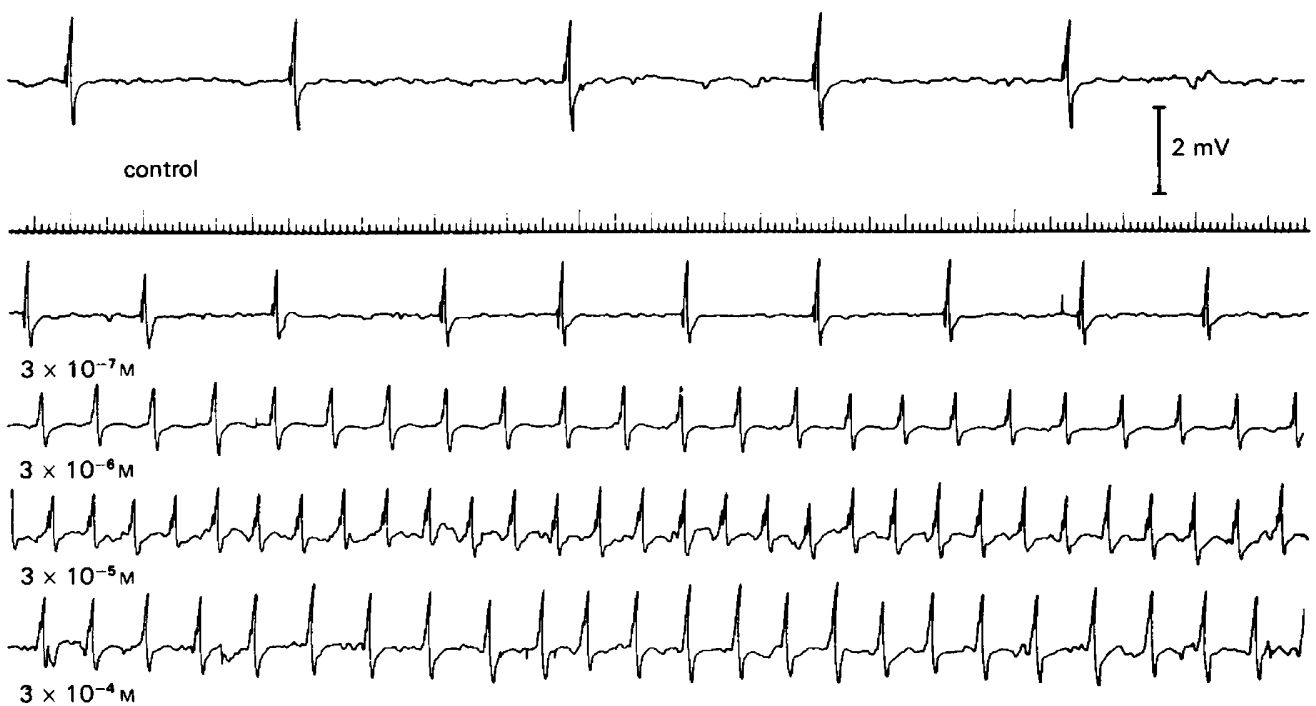

Text-fig. 3. Recording of electrical activity in the rat cauda epididymidis in response to different doses of phenylephrine. Time scale is in seconds.

mechanically only, were observed except with the highest concentrations, $10^{-4}$ or $10^{-3} \mathrm{M}$, which decreased the amplitude and in a few experiments the frequency. Phentolamine abolished the stimulant effect of adrenaline and isoprenaline. The frequency after isoprenaline was sometimes slightly decreased. Phentolamine did not abolish the effects of carbachol.

Propranolol and metoprolol. These beta-adrenergic blocking agents did not affect the spontaneous activity or abolish the effects of isoprenaline. Doses used were $10^{-6}, 10^{-5}$ and $10^{-4}$ $\mathrm{M}$, and for metoprolol, also $10^{-3} \mathrm{M}$. 
Atropine. This anticholinergic agent had no effect on the spontaneous activity, but at the doses used $\left(10^{-6}\right.$ or $\left.10^{-5} \mathrm{M}\right)$ the effects of carbachol were abolished.

\section{Discussion}

In this work all the agonists used (adrenaline, phenylephrine, isoprenaline and carbachol) increased the frequency, basal tension and amplitude of epididymal contractions. The dose-response curves were determined for every drug and the responses were stimulated by adrenergic agonists in an order of potency: adrenaline $>$ phenylephrine $>$ isoprenaline. This is the classical order of potency for alpha-adrenergic responses. It is generally assumed that the receptor in the vas deferens is of an alpha-type, and this seems also to be the case in the epididymal duct. Our experiments with alpha- and beta-blockers suggest that the effects of adrenaline, phenylephrine and also isoprenaline are mediated through an alpha-receptor. In contrast to the in-vivo results of Hib (1976), the two beta-receptor blockers used did not abolish the stimulatory action of the beta-adrenergic stimulant. Hib (1976) postulated the presence of a beta-type receptor in the epididymis. In general, however, beta-receptor activation produces relaxation in smooth muscles (e.g. uterus, intestine, vascular musculature).

The results obtained from pharmacological studies on the epididymis are in part dependent on dose, species and method, which might account for some of the contradictory results reported; e.g. adrenaline did not affect the frequency (Hib, 1975), phentolamine decreased the basal tension and frequency of contractions (da Silva e Souza et al., 1975), and orciprenaline did not have an effect on the cauda (Hib \& Caldeyro-Barcia, 1974). One explanation why a beta-blocker did not abolish the effects of a beta-adrenergic agent in this in-vitro study, although it did so in vivo (Hib, 1976), could be that the possible beta-adrenergic receptors are not accessible to an agonist or an antagonist. The stimulatory effect of isoprenaline would therefore be mediated through the alpha-adrenergic receptor at high concentrations.

Besides the adrenergic drugs, the cholinergic agent, carbachol, also had stimulatory effects on the smooth muscle of the rat epididymis. Similar observations have been reported with acetylcholine in vitro (Hib \& Caldeyro-Barcia, 1974) and in vivo (Hib, 1976). These results are consistent with the findings that in addition to the dense adrenergic innervation there is also a cholinergic input to the vas deferens and the ductus epididymidis (Baumgarten et al., 1971). It is, however, probable that this cholinergic motor innervation is of minor importance, since atropine has only a slight effect on the emission of spermatozoa in the boar (Dziuk \& Mann, 1963).

\section{References}

Baumgarten, H.G., Holstein, A.F. \& Rosengren, E. (1971) Arrangement, ultrastructure, and adrenergic innervation of smooth musculature of the ductuli efferentes, ductus epididymidis and ductus deferens of man. Z. Zellforsch. mikrosk. Anat. 120, 37-39.

da Silva e Souza, M.C., Gimeno, A.L. \& Gimeno, M.F. (1975) Pharmacological influences upon the contractile activity of isolated guinea pig epididymis. Acta physiol. LatinoAm. 25, 225-226.

Dziuk, P.J. \& Mann, T. (1963) Effect of atropine on the composition of semen and secretory function of male accessory organs in the boar. J. Reprod. Fert. 5, $101-108$.

Hib, J. (1975) Epididymal contractility in vitro. Effect of drugs. Acta physiol. LatinoAm. 25, 233-234.

Hib, J. (1976) Effects of autonomic drugs on epididymal contractions. Fert. Steril. 27, 951-956.

Hib, J. \& Caldeyro-Barcia, R. (1974) Neurohormonal control of epididymal contraction. In Physiology and Genetics of Reproduction, Part B, pp. 111-126. Eds
E. M. Coutinho \& F. Fuchs. Plenum Press, New York.

Knight, T.W. (1974) A qualitative study of factors affecting the contractions of the epididymis and ductus deferens of the ram. J. Reprod. Fert. 40, 19-29.

Melin, P. (1970) Effects in vivo of neurohypophysial hormones on the contractile activity of accessory sex organs in male rabbits. J. Reprod. Fert. 22, 283-292.

Risley, P.L. (1963) Physiology of male accessory organs. In Mechanisms Concerned with Conception, pp. 73-137. Ed. C. G. Hartman. Pergamon Press, New York.

Talo, A. \& Hodgson, B.J. (1978) Spike bursts in rabbit oviduct. I. Effect of ovulation. Am. J. Physiol. 234, E430-E438.

Talo, A., Jaakkola, U.-M. \& Markkula-Viltanen, M. (1979) Spontaneous electrical activity of the rat epididymis in vitro. J. Reprod. Fert. 57, 423-429. 